\title{
AN INVESTIGATION OF ARGON GAS ADDITIVES TO LPG ON THE TURBULENT LEAN PREMIXED FLAME CHARACTERISTICS FOR EV BURNER
}

\author{
${ }^{1}$ Sameh Hamed Elsayed, ${ }^{2}$ mahmoud elkady, ${ }^{3}$ Ahmed Abdelrazek Emara \\ and ${ }^{3}$ Amhed Mohamed Abelnaeim \\ ${ }^{1}$ Mechanical Power Engineering Department, Military Technical College \\ ${ }^{2}$ Mechanical Power Engineering Department, Faculty of Engineering, Al Azhar University, \\ ${ }^{3}$ Mechanical Power Engineering Department, Faculty of Engineering, Mattaria University,
}

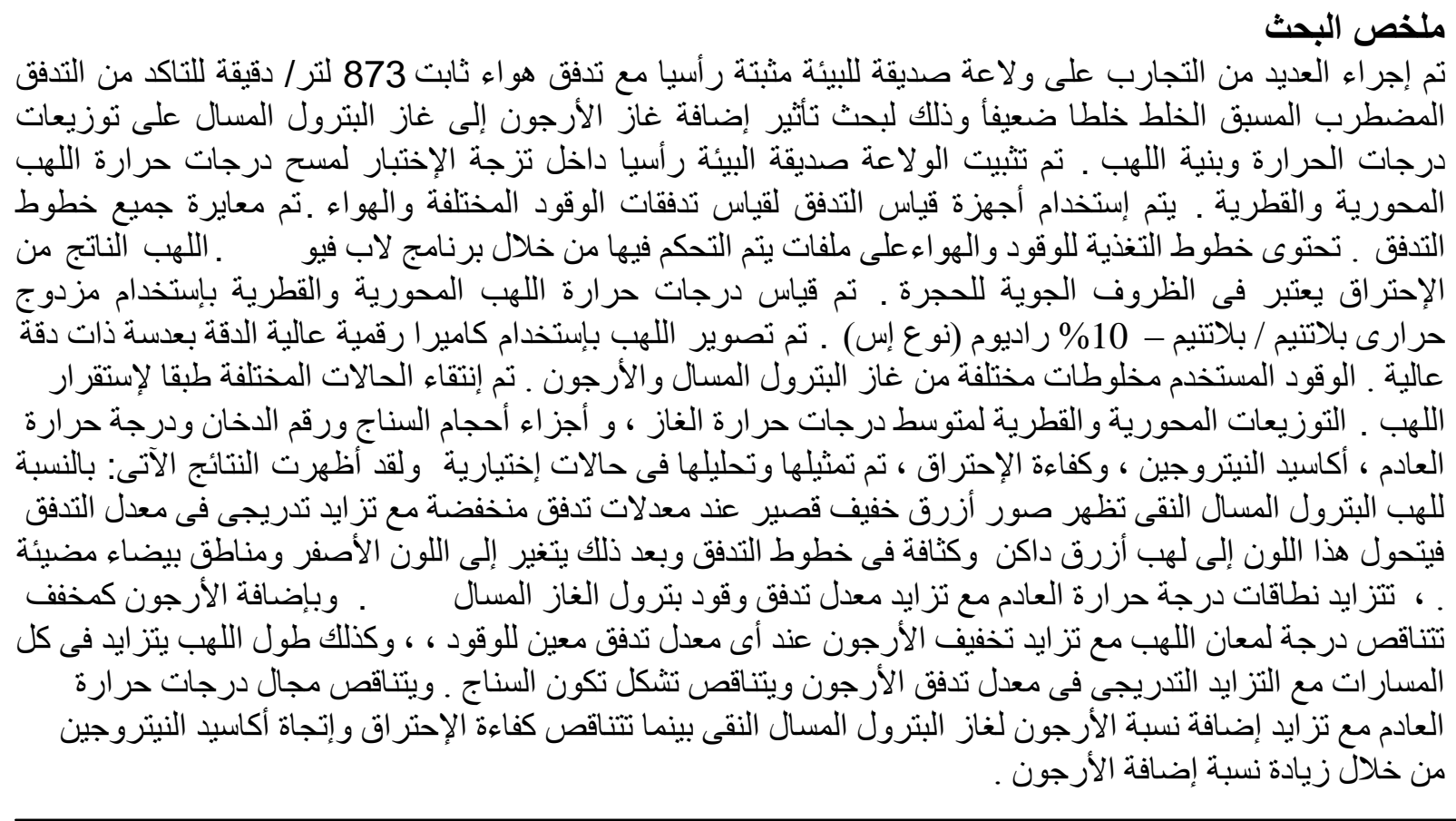

\begin{abstract}
:
A sets of experiments were done on a vertical environmental (EV) burner with fixed coflow air of 873 Lit /min to ensure turbulent lean premixed flow in order to study the effect of additon of argon mixture to the Liquefied Petroleum Gas on the temperature distributions and flame structure. The environmental (EV) burner assembly was fixed vertically in the test rig to scan the flame radially and axially. The flow rate of fuels, diluent and air were measured using rotameters. The whole supply lines were calibrated. The mixture of gases, air were injected through mixing pipes controlled with solenoid valves handled with a Labview program. The combustion flame was in room atmospheric conditions. The turbulent flame axial, radial temperature profile was measured using a shielded Platinum thermocouple type S. Flame images were taken using high resolution Canon 6D digital camera with high resolution lens . The fuel used was mixtures of different fuels of LPG, Argon. The choice of the different investigated cases was based on flame stability. The axial, radial distributions of mean gas
\end{abstract}


and exhaust temperature,smoke number,NOx and combustion efficiency, are presented and analyzed for selective cases.The results obtained indicate the following: for pure LPG flames the images show short light blue flames at low flow rates and with progressive increase of the fuel flow rate this color changed to dark blue flame then to yellowish and white luminous zone.The exhaust temperature ranges was increasing with increasing of fuel flow rate of LPG. By Ar addition the flame luminosity decreases with the increase of Ar dilution, also the flame length increased in all runs with the progressive increase of Argon flow rate while decreasing the soot formation, while the NOx trend, exhaust temperature and combustion efficiency decreased by increasing Argon percentage addition.

\section{Keywords: Environmental (EV) Burner, Liquefied Petroleum Gas, Platinum Thermocouple, Soot Formation, Turbulent Lean.}

\section{INTRODUCTION}

Lean combustion is employed in nearly all combustion technology applications, including gas turbines, boilers, furnaces, and internal combustion engines. This wide range of combustion devices attempts to take advantage of the fact that combustion processes operating under fuel lean conditions generate low emissions and attain high efficiency (Rankin et al 2007) [1]. Pollutant emissions are reduced because flame temperatures are typically low, reducing thermal nitric oxide formation. In addition, for hydrocarbon combustion, when leaning is accomplished with excess air, complete burnout of fuel generally results, reducing hydrocarbon and carbon monoxide emissions. For power generation, premixed gas turbine combustors need to be operated as lean as possible to secure sub-10 ppm concentrations of NOx emission. In a combustor under fuel-lean conditions, achieving stable combustion requires overcoming several inter-related problems such as flame stabilization, flame stability and extinction, and combustion oscillations or thermoacoustic instabilities which depend on the boundary conditions of the engine. Most of gas turbine injectors make swirl configurations that produce a central toroidal recirculation zones to provide the dominant flame stabilization mechanism (Yang et al 2005) [2]. Swirl increases fuel-air mixing, improves flame stabilization, and has a strong influence on flame characteristics and pollutant emissions (Emara et al 2009) [3]. Combustion efficiency can be greatly enhanced through good mixing of the fuel and combustion air. This can be achieved by introducing a sizeable shear layer between the fuel and air jets making internal recirculation leads to stability of flow and good mixing (A.Hussien) [4]. In combustion applications, compound-jet configurations have a very important role in enhancing combustion in premixed burners. Premixed flames occur when the fuel and the oxidizer are mixed upstream of the delivery to the combustion zone. (S. Habik et al 2002) [5]. In the design of modern lean premixed combustors, swirling flows play an important role. Vortex break down is nowadays the preferred flame holding mechanism. Swirl stabilized flames are rather compact and allow the design of smaller and lighter combustion chambers. Besides there is the advantage that no flame holders are needed in the hot regions of the flame and concequently there will be no need to cool such flame holders. The incoming fresh mixture shown in Fig. 1 is given a swirling motion which induces a recirculating bubble in the center of the jet.
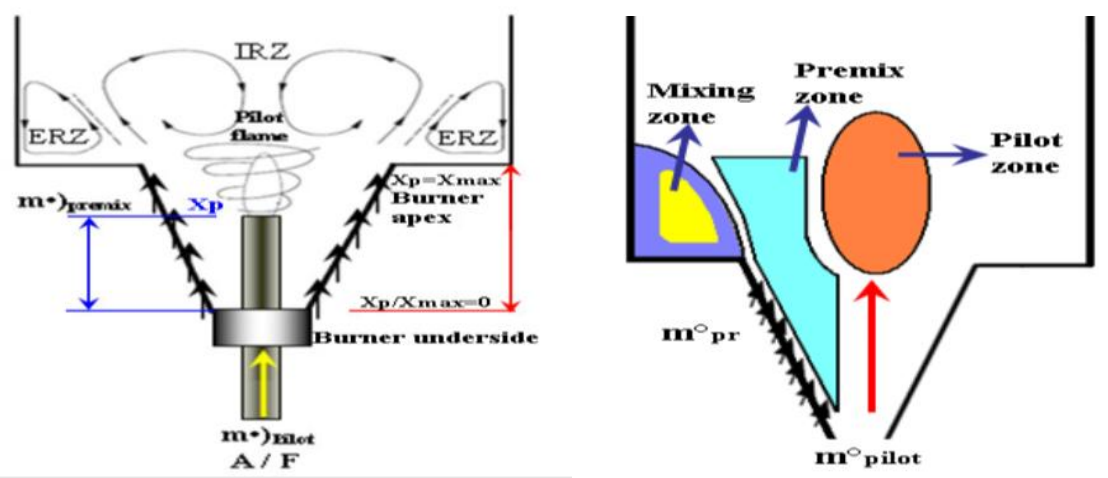

Figure 1. Sketch of the swirl stabilized burner flow (left) and flame zones (right) . 
This Central Recirculation Zone (CRZ), recirculating hot burnt gases, provides the heat necessary to preheat and ignite the incoming air-fuel mixture (S. Habik et al 2002) [5]. Moreover, swirling flows enhance mixing of the fuel with the air flow, for both gaseous and liquid fuels. ABB and ALSTOM now presents an ecological as well as economical solution to the NOx emission problems by introducing a new dual fuel dry low-NOx burner which is designed to meet NOx emission limits down to $9 \mathrm{ppm}$ on natural gas. The burner is a full size conical swirl burner designed by ABB with a crosssectional area expansion ratio of 4 for flame stabilization as shown in Fig..2. It consists of two conical halves shifted with respect to each other in radial direction (Guyot et al 2007) [6]. The diameter of each cone-half at the outlet is $\mathrm{D}=82 \mathrm{~mm}$. This diameter is used as a reference length for all characteristic numbers. The air flow enters the cone circumferentially through two lateral inlet slots of constant width. This generates a strong azimuthal velocity component resulting in a high degree of swirl (Swirl no. $=0.7$ ). Together with the area jump at the burner outlet, this leads to a vortex breakdown near the burner mouth followed by a recirculation zone where the flame is stabilized aerodynamically (Duwig et al 2007) [7]. During the combustion process, mixing of swirling air and main fuel results in nearly premixed combustion (Albrecht et al 2006) [8] .During combustion, the recirculation of hot combustion gases, inside the flame, leads to a second oxidation and to a reduction of carbon monoxide. The disadvantages of this type of flame stabilization are flow instabilities accompanied by complex three-dimensional coherent structures (Lacarelle et al 2008) [9].

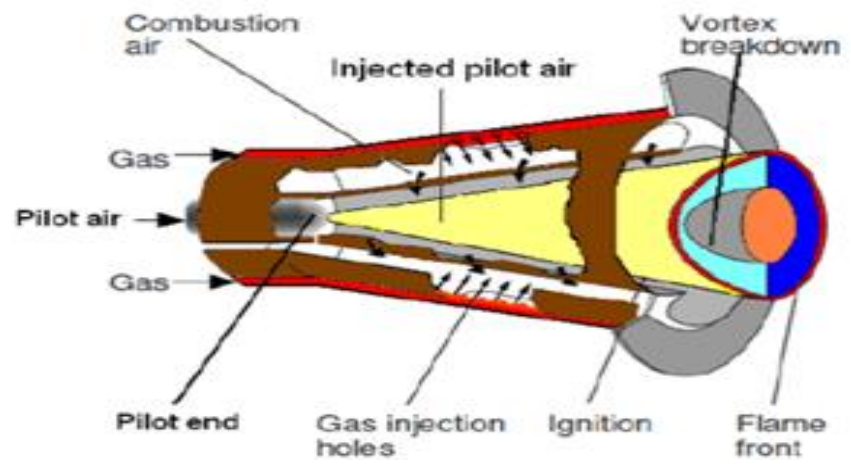

Figure 2. Sketch of swirl stabilized EV burner .

The investigation of injected mixture of Argon gas additives to the liquefied petroleum gas (LPG) in different concentrations on coflowing jet turbulent lean premixed flames is significant. Argon ( $\mathrm{Ar}$ ) is the third most common gas in the Earth's atmosphere. About 700,000 tones of Ar are produced worldwide every year. Ar occurs naturally in air, and is readily obtained as a byproduct of cryogenic air separation in the production of $\mathrm{O}_{2}$ and $\mathrm{N}_{2}$. Ar has been already used in ICE. It has an effect in combustion increasing efficiency $[10,11]$. There are two classes of additives that may be added to the hydrocarbon fuel either to suppress soot emissions or to promote it. These are explained as follows:

(i) Additives that suppress soot emission: These additives include inert gases such as $\mathrm{Ar}, \mathrm{He}$ and $\mathrm{N}_{2}$, hydrogen, $\mathrm{CO}_{2}, \mathrm{H}_{2} \mathrm{O}$ and $\mathrm{SO}_{2}$.Inert gases generally decrease the tendency to soot formation see Fig. 3 the left side which shows the effect of various additives to the fuel in suppressing soot, as determined by the increase in fuel flow at smoke point with increasing fuel additives. Also Figure 3 shows Bacharach scale which gives a relation between soot concentrations with smoke number.

(ii) Additives that promote Soot formation: These additives include:

- Halogens (particularly bromine): These act by catalyzing radical recombination, thus neutralizing excess $\mathrm{OH}$ radicals which could otherwise oxidize soot or soot precursors.

- Oxygen: The effect of oxygen addition to the fuel is complex. Some authors found that $\mathrm{O}_{2}$ acts as soot promoters while others found it to be a soot inhibitor; for example: (a) In ethylene flames, small addition of $\mathrm{O}_{2}$ result in pronounced increased soot emissions. The presence of $\mathrm{O}_{2}$ accelerates the pyrolysis or polymerization reactions occurring in the ethylene; (Wright et al 
1961) [12] This is also confirmed by the studies on ethane, butane, propane, propylene and benzene diffusion flames; (Schug K.P et al 1980) [14] .(b) In propane, butane and propylene, $\mathrm{O}_{2}$ suppresses soot emissions; (Gay et al 1961) [15].
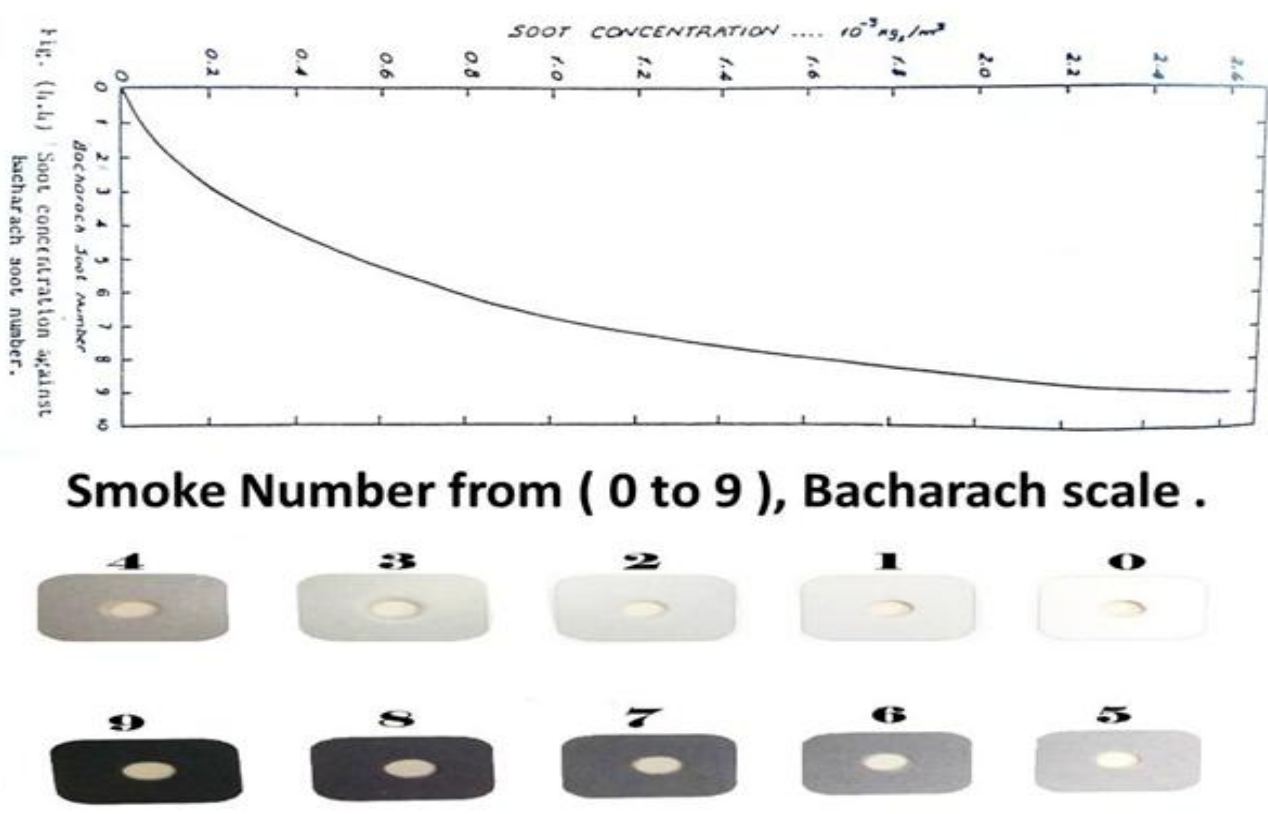

Figure 3. Relation between soot concentration with smoke number (Bacharach scale) , [13].

\section{EXPERIMENTAL SET UP, FACILITIES AND EXPRIMENT PERFORMANCE}

The present work aims to study the effect of adding Argon gas additives to the liquefied petroleum gas (LPG) on the temperature distribution and flame structure. The coflow air was fixed through the whole experiment at $873 \mathrm{Lit} / \mathrm{min}, \mathrm{P}=1.6 \mathrm{Bar}$. The measurement system can be configured to measure some or all of the flame parameters depending upon the application requirements. The measurement results can be used to predict and diagnose combustion phenomenon. The assembly and schematic diagram of system set-up is shown in Figures. $4 \mathrm{a}, 4 \mathrm{~b}$.

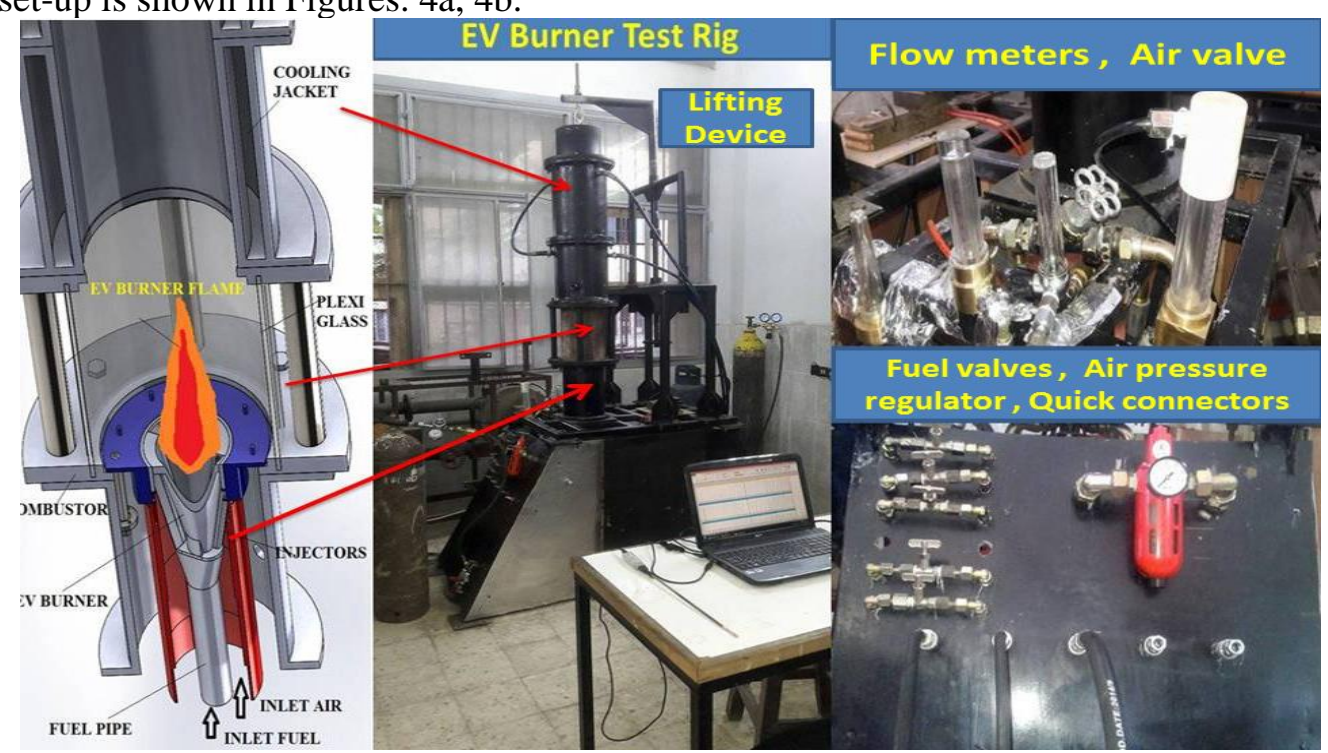

Figure 4a . Assembly of manufactured environmental (EV) burner test rig. 


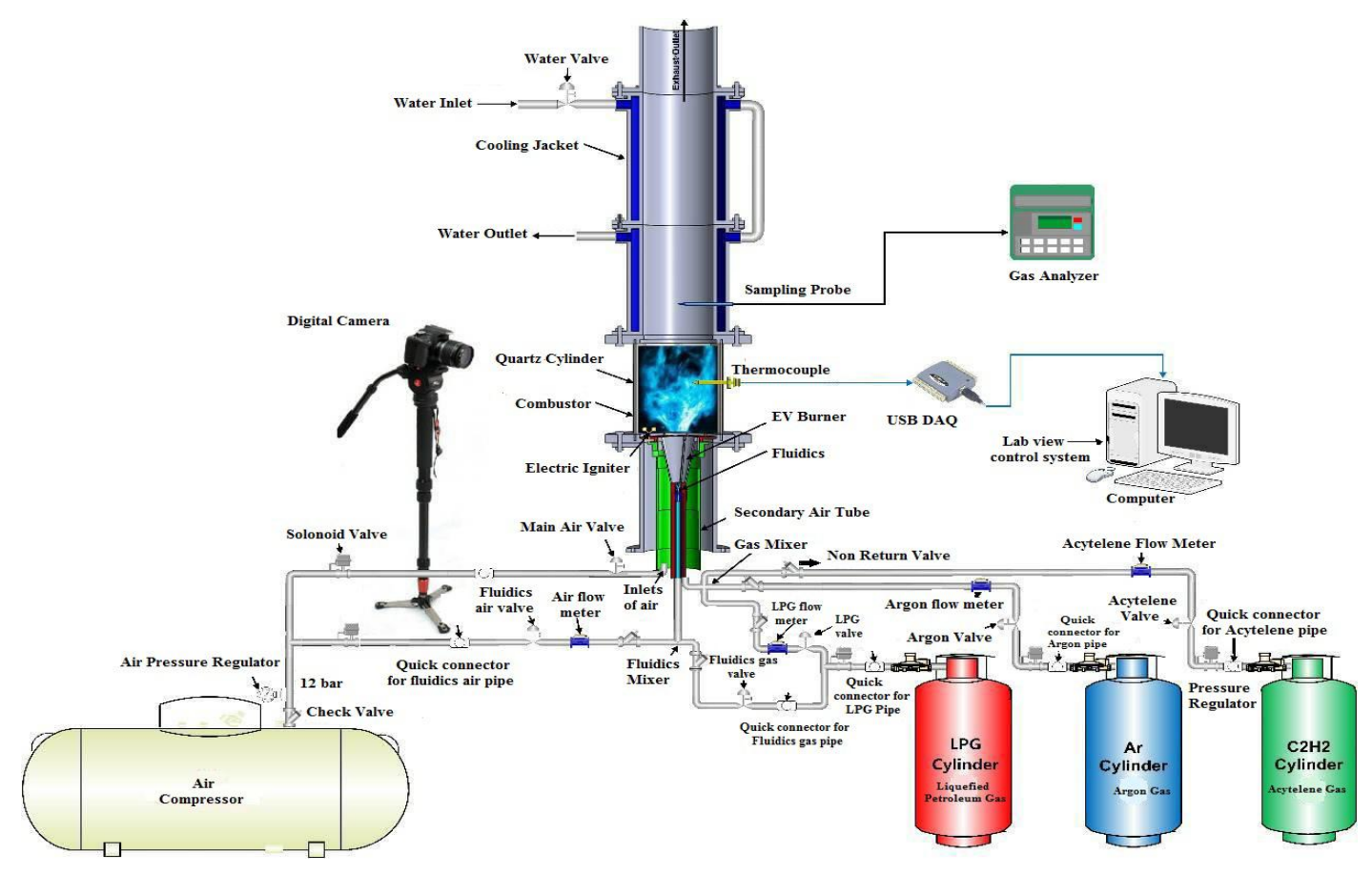

Figure 4b. Schematic diagram of manufactured environmental (EV) burner test rig .

The lean premixed co flowing jet turbulent flames were established on a flat EV burner with an air coflow injected upstream the flow (Figure. 5) (Emara et al 2011) [16]. The manufacturing process for the EV burner components as shown in Figure 5. Was done on CNC milling-turning machine due to its high degree of precision and accuracy. The EV burner Figure.6. Shows the modifications done in the environmental (EV) burner after being manufactured in order to adapt the burner for cold and hot flow Conditions. These modifications includes:- 1- A mixer of gases fixed at the top of fuel pipe with three inputs for mixing of different gases. 2- A burner flange for vertical suspension of EV burner in the test rig. 3- A secondary cylindrical air tube threaded from one side with the burner flange while its other side is closed by a flange with four inputs of air to take pure pressurized air from the compressor 12 bar and this four inputs with circular outputs for swiriling the air coming from the compressors in order to improve mixing of gases with air and for combustion enhancement (Sameh Hassan, Emara, M.Elkady et al 2016) [17] .

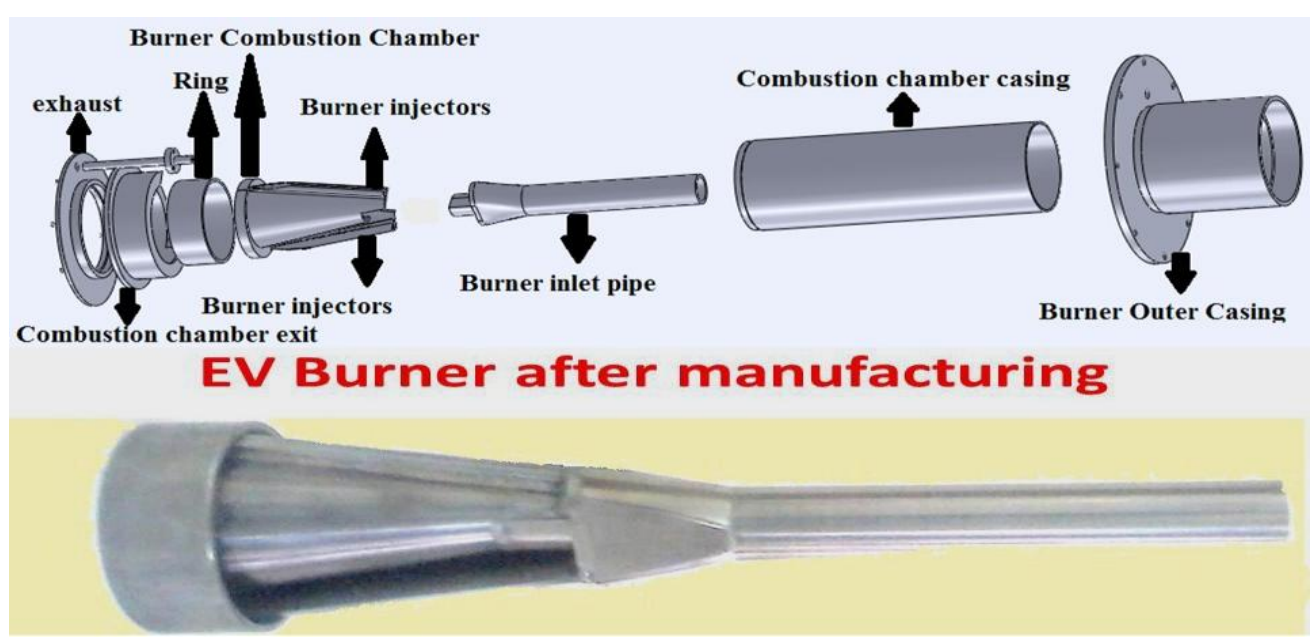

Figure 5. Disassembly of manufacturing components of environmental (EV) burner . 


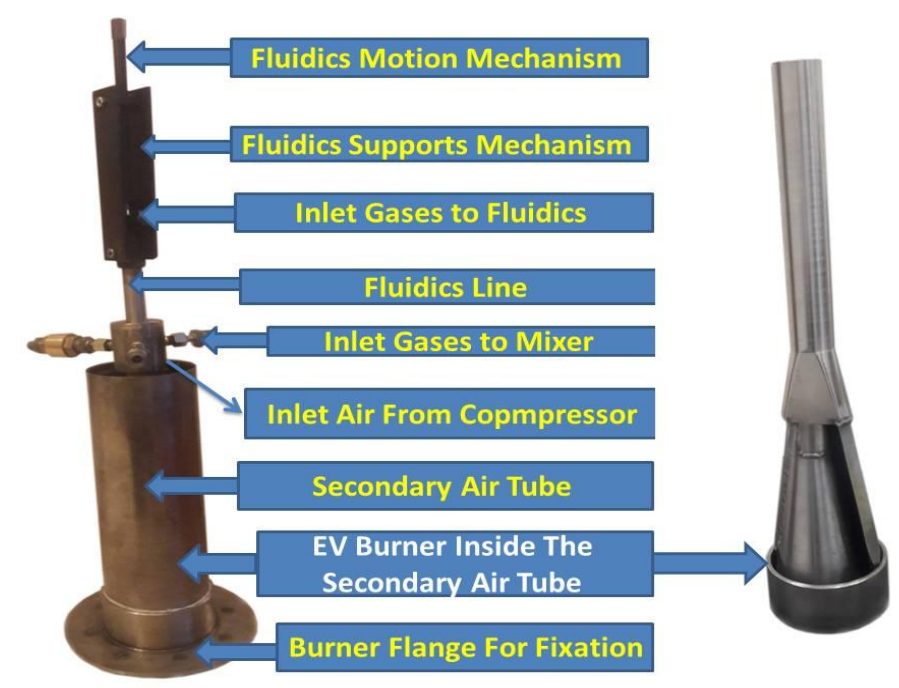

Figure 6. Fuel and air connections in environmental (EV) burner.

The combustion flames were in room atmospheric conditions with room disturbances controlled by surrounding A cylindrical silica glass was put upward the burner rim with $30 \mathrm{~cm}$ length and $1 \mathrm{~cm}$ thickness in order to treat such flames as free jet turbulent lean premixed flames and through this silica transparent glass we can visualize flame and taking a lot of digital images at different conditions while at the same time keeping its confined characteristics. Also the silica glass was replaced by a stainless steel cylindrical tube (Combustor) of $30 \mathrm{~cm}$ length and with 14 vertical holes of $1 \mathrm{~cm}$ diameter on its left side for inserting thermocouple through these holes for inflames radial and axial measurements. The instrumentation of the burner including the PC was connected in such a way to provide safe ignition conditions.

The control card was powered by a 5V DC power supply. Air compressor 12 bar regulated to 1 bar gauge pressure supply air mass flow rates. Wide range of flow rates, mostly dry, is measured by calibrated standard flow rotameters (model KI-USA) and is controlled by precision needle valves. In order to admit accurate flow rates of both the gaseous fuel and the coflowing air, four flow supply and metering systems for LPG, Argon, Acetylene and air are used.In this work fuel and air flow rates measurements are made using rotameters manufactured by Dwyer Instruments Inc. Since all the rotameters used are calibrated for air at standard pressure and temperature, the flow-rate readings taken were corrected according to the calibration equations supplied by the manufacturer for the flow pressure. Five solonid valves were used and controlled by Lab VIEW program. The turbulent lean premixed flame,axial and radial temperature profile were measured using a shielded-aspirated thermocouple pt/ Pt $-10 \%$ Rhodium (type S) with maximum temperature of $1800{ }^{\circ} \mathrm{C}, \leq 250 \mu \mathrm{m}$ diameter, $\pm 0.5 \%$ uncertainty limit and response time of 0.3 second. A digital muffle furnace is incorporated for the calibration and the results showed a difference of 1-2\%.

The probe offers the minimal possible disturbances. The output voltage from the thermocouple is acquired using the Omega interface program thermocouple reader and PC. Radiation error is due to radiant heat transfer from the temperature sensor to its surroundings while conduction error is due to time lag needed to heat the thermocouple bead. The magnitude of the thermocouple errors can be reduced by taking several relatively simple steps: (i) use as small thermocouple bead as possible. (ii) Use new shiny thermocouples.

The low emissivity minimizes radiational heating. Using a shielded-aspirated thermocouple reduces the error in the average trace. Highest accuracy is attained when using small diameter shieldedaspirated thermocouples (Shannon et al 2002), (Shaddix et al 1998), (Jones et al 1995) [18, 19, 20]. Flame images were taken using Canon 6D 20.2MP full frame camera with high resolution Lens 70 - 
200 F2.8L IS II USM with sensor having a speed of up to $3.7 \mathrm{fps}$ was used to obtain visual images of the flames under different operating conditions. All shots were taken in the night vision mode with shutter speed of $1 / 60 \mathrm{~s}$ to express the average flame shape. The visual flame length was measured by comparing the flame length in the photo by a reference length scale. Injecting of diluents affects the turbulent lean premixed process, flame length and temperature distribution through the flame. A smoke probe was used for detecting the smoke number for some selective cases.

\subsection{EXPERIMENT PERFORMANCE}

Before performing the experiment, the system must be completely free of leaks to prevent errors in flow rate measurements and maintain a safe working environment. The flow rate of the coflowing air was firstly adjusted which kept

constant through the whole experiments at $873 \mathrm{Lit} / \mathrm{min}$ then the rate of LPG and at last the rate of the diluents. A series of experiments were performed as presented in Table 2A, 2B. The mixing of gases was based on the volume flow rate of gases injected to the burner.

The choice of the different cases was based on flame stability. The air flow rate was kept constant as mentioned before in all cases. The fuel used was LPG with flow rate from 20 up to $32 \mathrm{Lit} / \mathrm{min}$, Argon flow rate up to $12 \mathrm{Lit} / \mathrm{min}$. The total mixture flow rate $(\mathrm{LPG}+$ Argon) didn't exceed $40 \mathrm{Lit} / \mathrm{min}$ in order to prevent the flame instabilities. In Runs (1A to 1E) representing the base line only LPG and air were used. In Runs (2A to 2C), air and Ar were applied together with LPG where argon was added by $10 \%$ and LPG was added by $90 \%$.In the Runs (3A to 3D) air and Argon were applied together with LPG where argon was added by $20 \%$ and LPG was added by $80 \%$.

Finally in Runs (4A to 4D) air and Argon were applied together with LPG where argon was added by $30 \%$ and LPG was added by $70 \%$. In order to detect the temperature distribution through the flame, the temperature was measured in axial and radial directions. The reference point of all measurements was at " 0 " corresponding to the center of the burner Figure 7. And the combustor where the turbulent lean premixed flame issuing from the EV burner pass through it apperars with its dimensions as shown in Figure 8.

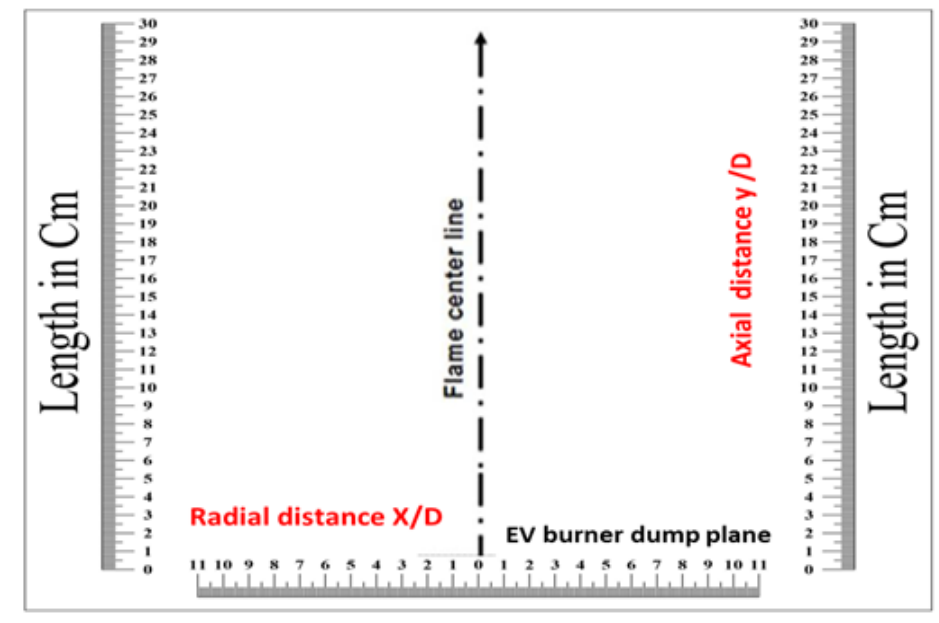

Figure 7. Schematic representation of axial \& radial directions . 


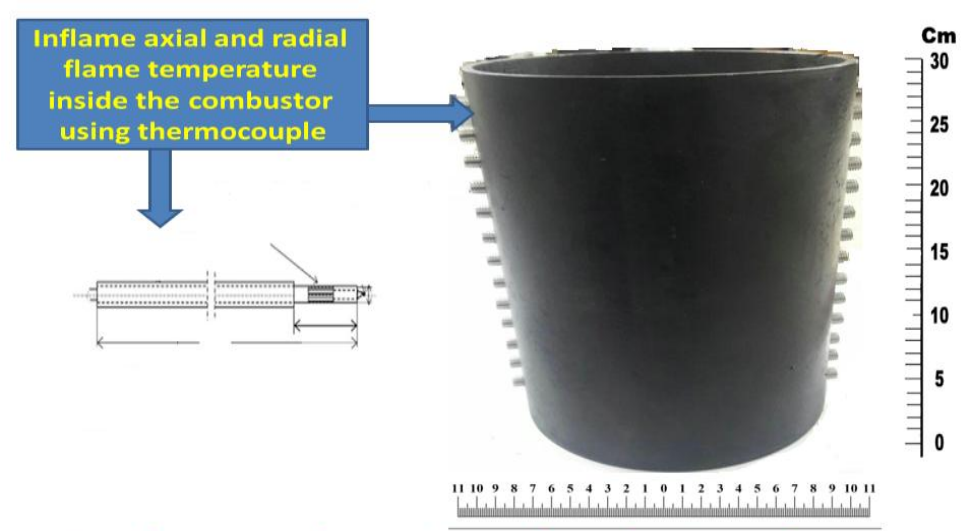

\section{Combustor Volume $30 \mathrm{~cm}$ length $22 \mathrm{~cm}$ diameter}

Figure 8. Combustor layout and dimensions .

Table 2A . CASE'S BOUNDARY CONDITIONS

\begin{tabular}{|c|c|c|c|c|c|}
\hline Case No & $\begin{array}{c}\text { Air flow rate } \\
\text { (lit / min) }\end{array}$ & $\begin{array}{c}\text { LPG flow rate } \\
\text { (lit / min) }\end{array}$ & $\begin{array}{l}\text { Argon flow rate } \\
\text { (lit / min) }\end{array}$ & $\begin{array}{c}\text { Total mixture } \\
\text { flow rate (lit/min) }\end{array}$ & $\Phi$ \\
\hline Run 1A & \multirow{16}{*}{873} & 20 & nil & 20 & 0.63 \\
\hline Run 1B & & 24 & nil & 24 & 0.75 \\
\hline Run 1C & & 26 & nil & 26 & 0.82 \\
\hline Run 1D & & 28 & nil & 28 & 0.88 \\
\hline Run 1E & & 32 & nil & 32 & 1 \\
\hline Run 2A & & 25.2 & 2.8 & 28 & 0.79 \\
\hline Run 2B & & 28.8 & 3.2 & 32 & 0.90 \\
\hline Run 2C & & 32.4 & 3.6 & 36 & 1 \\
\hline Run 3A & & 22.4 & 5.6 & 28 & 0.70 \\
\hline Run 3B & & 25.6 & 6.4 & 32 & 0.80 \\
\hline Run 3C & & 28.8 & 7.2 & 36 & 0.90 \\
\hline Run 3D & & 32 & 8 & 40 & 1 \\
\hline Run 4A & & 19.6 & 8.4 & 28 & 0.61 \\
\hline Run 4B & & 22.4 & 9.6 & 32 & 0.70 \\
\hline Run 4C & & 25.2 & 10.8 & 36 & 0.79 \\
\hline Run 4D & & 28 & 12 & 40 & 0.88 \\
\hline
\end{tabular}

Table 2B . CASE'S BOUNDARY CONDITIONS

\begin{tabular}{|c|c|c|c|c|c|}
\hline Case No & NOx (ppm) & Texh $\left({ }^{\circ} \mathbf{C}\right)$ & ๆComb \% & Smoke No & $\begin{array}{c}\text { Flame temperature } \\
\left({ }^{\circ} \mathbf{C}\right)\end{array}$ \\
\hline Run 1A & - & 461 & 50.06 & - & - \\
\hline Run 1B & 6.23 & 571 & 52.59 & - & - \\
\hline Run 1C & 6.45 & 652 & 55.93 & $\checkmark$ & $\checkmark$ \\
\hline Run 1D & - & 725 & 58.17 & - & - \\
\hline Run 1E & 14.7 & 792 & 56.14 & - & $\checkmark$ \\
\hline Run 2A & 4.6 & 599 & 52.36 & - & $\checkmark$ \\
\hline Run 2B & 9.8 & 734 & 57.63 & - & - \\
\hline Run 2C & 11.1 & 795 & 56 & - & - \\
\hline Run 3A & 4.3 & 561 & 55.64 & - & - \\
\hline Run 3B & 6.2 & 585 & 51.28 & $\checkmark$ & - \\
\hline Run 3C & 7.8 & 705 & 55.61 & - & - \\
\hline Run 3D & - & 752 & 53.85 & - & - \\
\hline Run 4A & - & 451 & 50.52 & - & - \\
\hline Run 4B & - & 521 & 51.80 & - & - \\
\hline Run 4C & 8.4 & 570 & 50.91 & - & - \\
\hline Run 4D & - & 685 & 55.84 & - & - \\
\hline
\end{tabular}


Runs (1A to 1E): Includes temperature measurements for Runs (1C) in radial direction at different axial distances (from 2 to $18 \mathrm{~cm}$ ) from the EV burner rim (x/D from 0 to 1.6 ) representing different zone colors of the flame [1,2]. The temperature was also measured axially (from 0 to $18 \mathrm{~cm}$.) for Runs (1C) at the center of the flame (y/D from 0 to 1), also the smoke number was detected at Run (1C), while the trends of exhaust temperature, NOx, and combustion efficiency was detected through the whole Runs (1A to 1E).

Runs (2A to 2C): Includes temperature measurements for Runs (2A) in radial direction at different axial distances (from 2 to $18 \mathrm{~cm}$ ) from the EV burner rim (x/D from 0 to 1.6 ) representing different zone colors of the flame]. The temperature was also measured axially (from 0 to $18 \mathrm{~cm}$.) for Runs (2A) at the center of the flame (y/D from 0 to 1 ).

Runs (3A to 3D): Includes temperature measurements for Runs (3B) in radial direction at different axial distances (from 2 to $18 \mathrm{~cm}$ ) from the EV burner rim (x/D from 0 to 1.6) representing different zone colors of the flame. The temperature was also measured axially (from 0 to $18 \mathrm{~cm}$.) for Runs (3B) at the center of the flame (y/D from 0 to 1), also the smoke number was detected at Run 3B.

Runs (1C and $3 \mathrm{~B})$ : Includes the influence of argon addition on mean flame temperature along axial distance at $\Phi=0.8$ was detected.

Runs (2A to $2 \mathrm{C}$ and $3 \mathrm{~A}$ to $3 \mathrm{C}$ ): Includes graph for the variation of exhaust temperature with input volume flow rate of mixture of LPG and 10-20\% argon, also a graph show the relation between NOx emissions and flow rate of mixture of LPG and 10-20\% argon.

Runs (2A to 2C, 3A to 3C, 4A to 4C): Includes graph for the variation of combustion efficiency of a fuel mixture of ( LPG \& Argon ) at different percentages .

\section{RESULTS AND DISCUSSIONS}

The results obtained in the sixthteen investigated cases and their discussions are given in the following:

\section{Runs (1A to 1E):}

The temperature distribution is presented in Figure 9 which shows axial measurements in definite points according to flame zones with radial variation.. The temperature increased in the direction of flame boundaries to the maximum temperature of $1091,1052,902{ }^{\circ} \mathrm{C}$ at $\mathrm{Y}$ (axial distance) $=2,4$, and $6 \mathrm{~cm}$ from the burner dump plane respectively, also the other radial variations at Y ( axial distance) from $8 \mathrm{~cm}$ up to $18 \mathrm{~cm}$ were measured and appear in Figure 9 run 1C. The temperature of the flame increased along the center of the flame in axial direction the max. flame temperature reaches about $1091{ }^{\circ} \mathrm{C}$, which was in an axial distance of $\mathrm{y} / \mathrm{D}=0.12$ about $1 \mathrm{~cm}$ apart from the burner rim see Figure 10 run $1 \mathrm{C}$. The smoke number was detected by a special smoke probe and according to Bacharach scale with its curve the soot volume fraction (S.V.F) range was detected to be $(0.05-0.09 \mathrm{ppm})$, see Figure 11. The visible flame was captured by a precise digital camera Canon 6D Figure 12 and the flame length was measured through its image in the silica glass which shows that the flame length increase by increasing the pure LPG flow rate the images show short light blue flames at low flow rates and with progressive increase of the fuel flow rate this color changed to dark blue flame then to yellowish and white luminous zone Finally the exhaust temperatures, NOx trend and combustion efficiency were detected for the runs (1A to 1E) which appears in Figures 13 Panel a indicates, the increase of the exhaust temperature with increasing the fuel flow rate of pure LPG, while panel $b$ of Figure 13 shows the relation between the NOx emissions with increasing the fuel flow rate of pure LPG among the selected runs (1A to 1E). The NOx emissions lower valueis almost around $6.23 \mathrm{ppm}$ run $1 \mathrm{~B}$ at Texh $=571{ }^{\circ} \mathrm{C}$, also the NOx emissions were increasing by increasing of pure LPG flow rates. Figure 13 panel c, shows the relation between combustion efficiency and the flow rates of pure LPG for the same selective cases mentioned before. Its maximum value around $56.14 \%$ at $\Phi=1.0037$ run $1 \mathrm{E}$. 


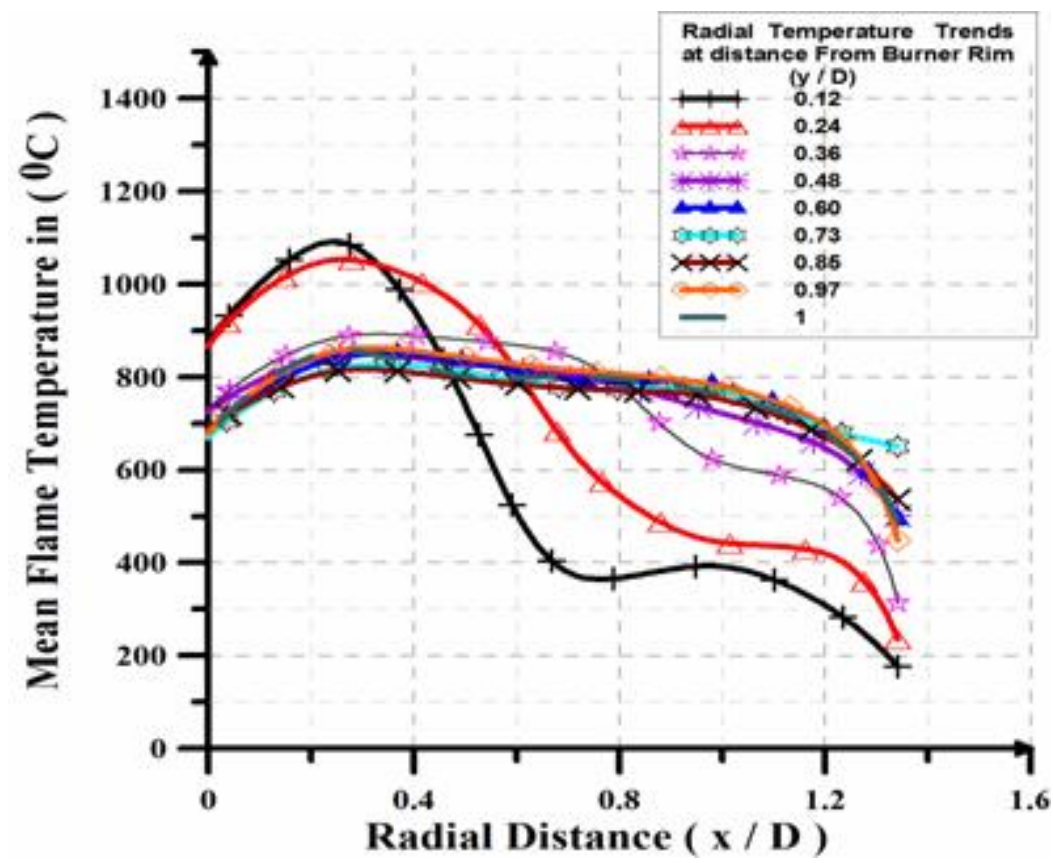

Figure 9.Temperature distribution across the flame in run 1C.

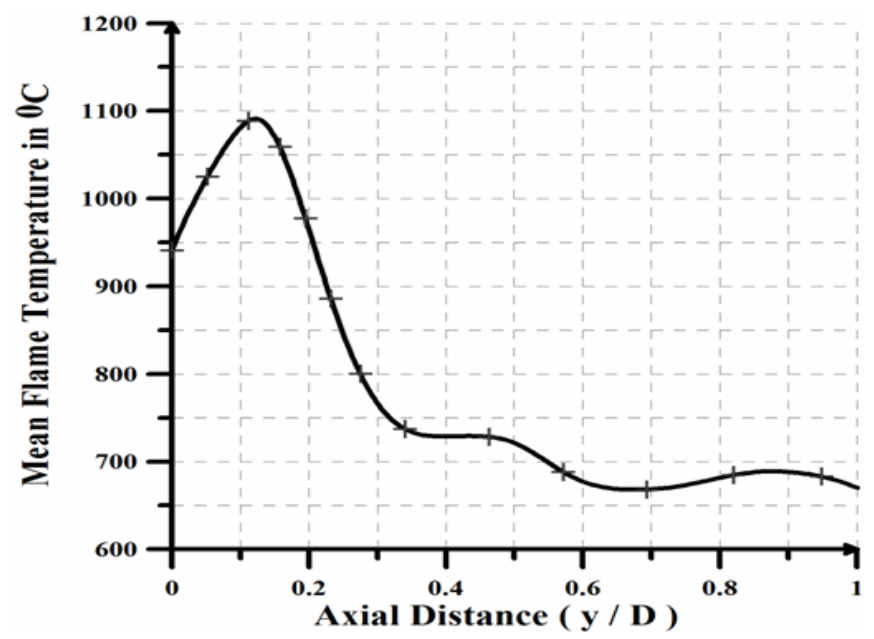

Figure 10. Temperature distribution through the center of the flame in run $1 \mathrm{C}$.

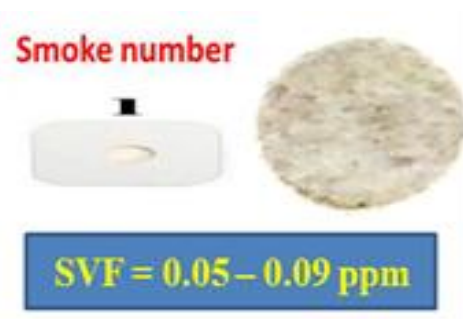

Figure 11. Smoke number at run $1 \mathrm{C}$ 

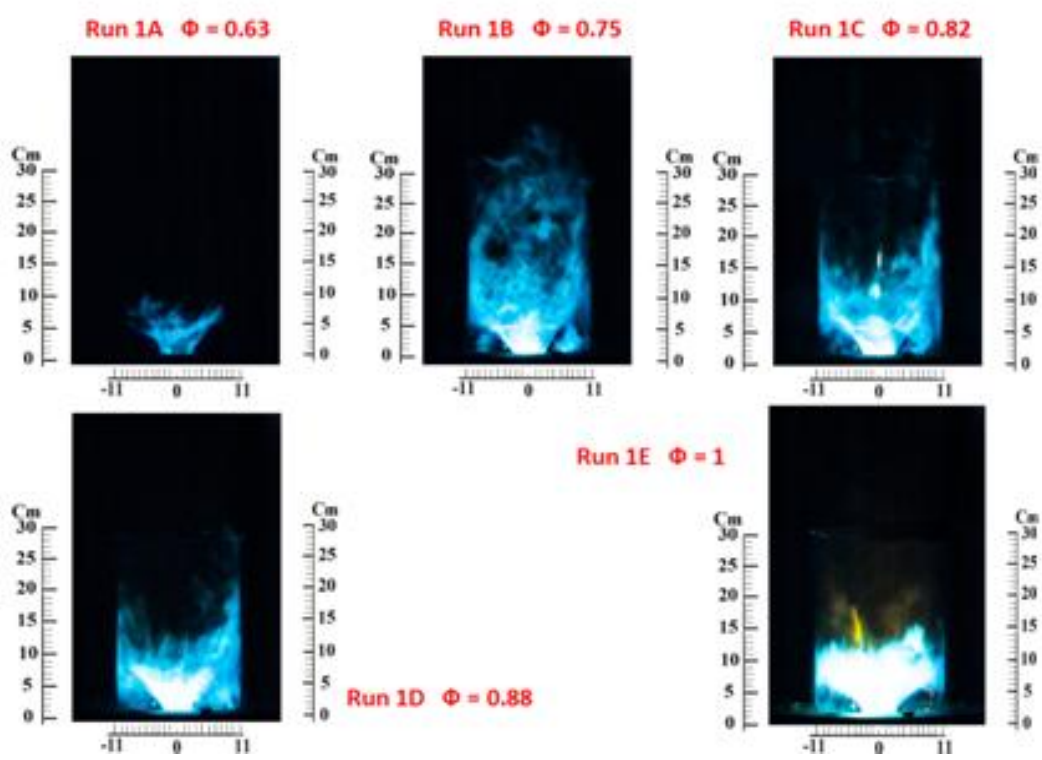

Figure 12. Visual images of the pure LPG turbulent lean premixed Flames at varying input volume flow rates; [Runs 1A to 1E].

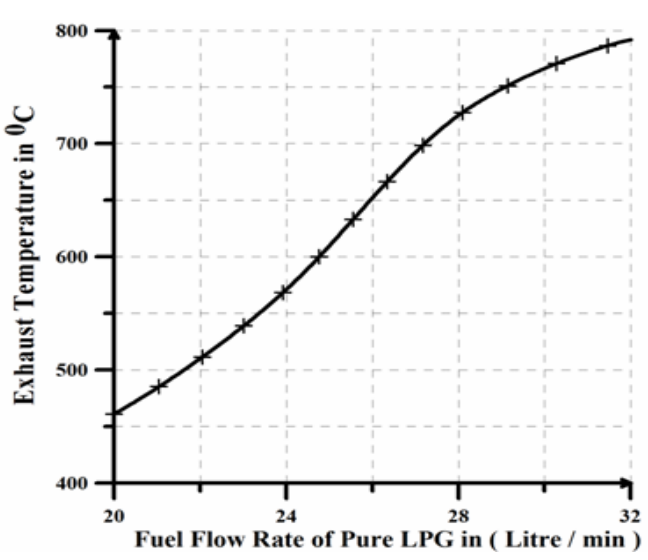

Panel a: variation of exhaust temperature with

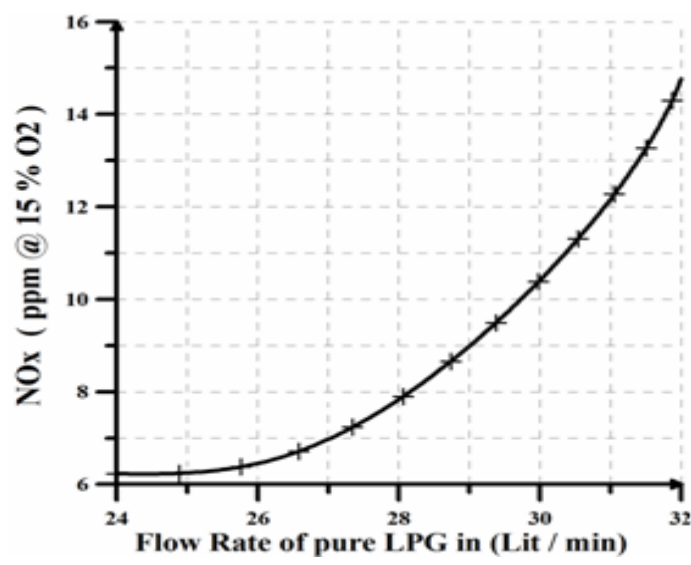

Panel b: variation of NOx with the flow rate of pure LPG

the flow rate of pure LPG.

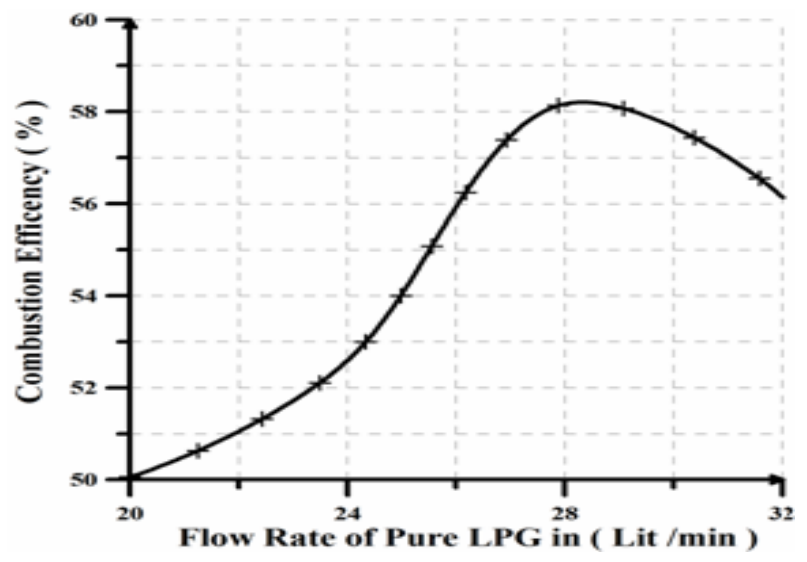

Panel c: variation of combustion efficiency with the flow Rate of pure LPG

Figure 13. Panels a, b, c variations of exhaust temperature, NOx, combustion efficiency with flow rate of pure LPG Runs (1A to 1D) 


\section{Runs (2A to 2C):}

The temperature of the flame increased along the center of the flame in axial direction the maximum. flame temperature reaches about $1051.4{ }^{\circ} \mathrm{C}$, which was in an axial distance of $\mathrm{y} / \mathrm{D}=0.12$ about $1 \mathrm{~cm}$ apart from the burner rim see Figure 14 run $2 \mathrm{~A}$. The temperature distribution is presented in Figure 15 which shows axial measurements in definite points according to flame zones with radial variation. The temperature increased in the direction of flame boundaries to the maximum temperature of 1270,1033 , $880{ }^{\circ} \mathrm{C}$ at $\mathrm{Y}$ (axial distance) $=2,4$, and $6 \mathrm{~cm}$ from the burner dump plane respectively, also the other radial variations at $\mathrm{Y}$ (axial distance) from $8 \mathrm{~cm}$ up to $18 \mathrm{~cm}$ were measured and appear in Figure 14 run $2 \mathrm{~A}$.

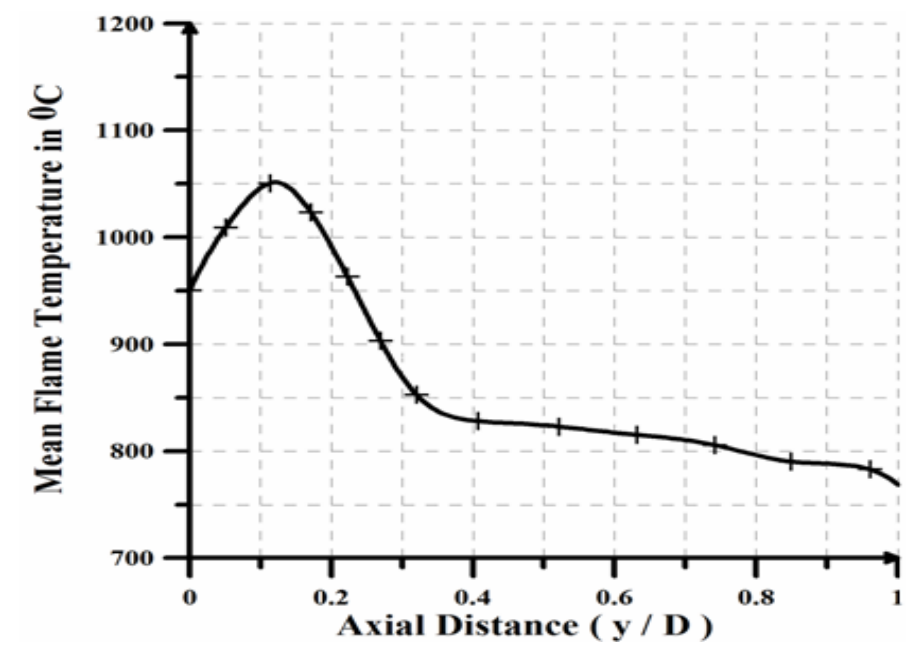

Figure 14.Temperature distribution through the center of the flame in run $2 \mathrm{~A}$.

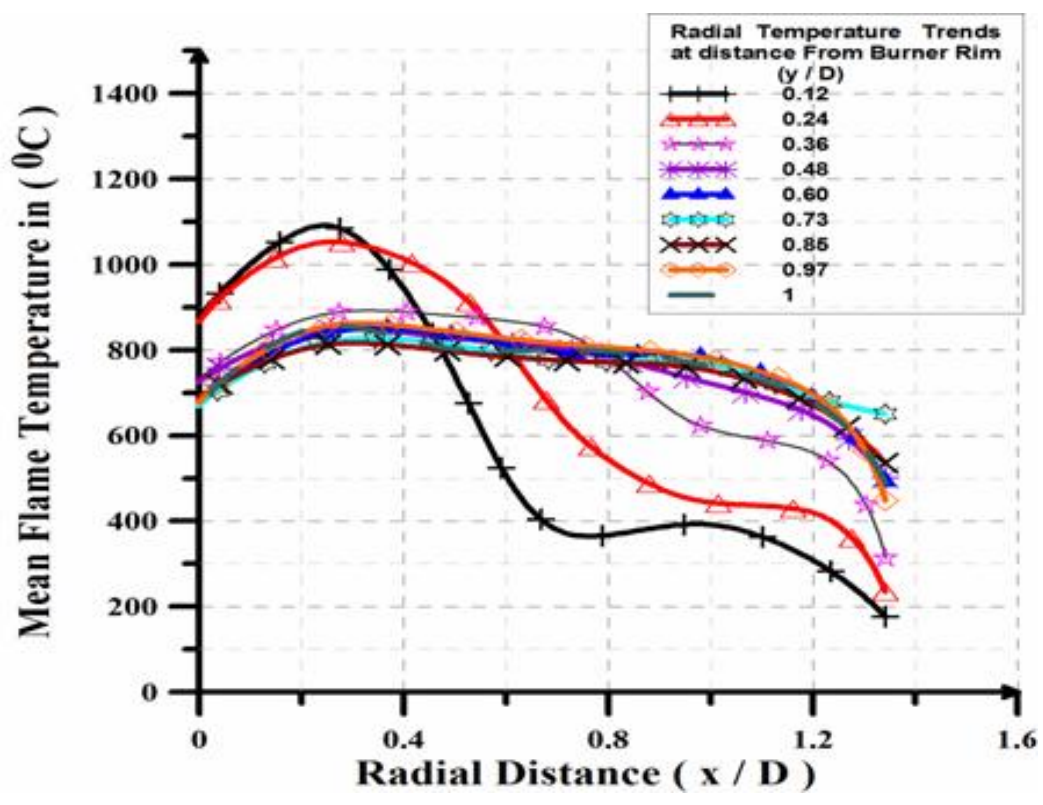

Figure 15.Temperature distribution across the flame in run $2 \mathrm{~A} . \Phi=1.0037$.

\section{Runs (3A to 3D):}

The fuel was modified by using a mixture of $80 \%$ LPG and $20 \%$ Argon. As in the previous runs, the radial variation of temperature distribution was measured in definite axial positions as shown in Figure 16.run 3B. The temperature increased in the direction of flame boundaries to the maximum temperature of $1275,1051,895{ }^{\circ} \mathrm{C}$ at $\mathrm{Y}$ (axial distance) $=2,4$, and $6 \mathrm{~cm}$ from the burner dump plane respectively, also the other radial variations at $\mathrm{Y}$ ( axial distance) from $8 \mathrm{~cm}$ up to $18 \mathrm{~cm}$ were measured and appear in Figure 16, also the smoke number was detected in Figure 17 which appears 
that it was decreased to smoke number zero due to argon addition .The temperature of the flame increased along the center of the flame in axial direction the maximum flame temperature reaches about $1039{ }^{\circ} \mathrm{C}$, which was in an axial distance of $\mathrm{y} / \mathrm{D}=0.12$ about $1 \mathrm{~cm}$ apart from the burner rim see Figure 18 .

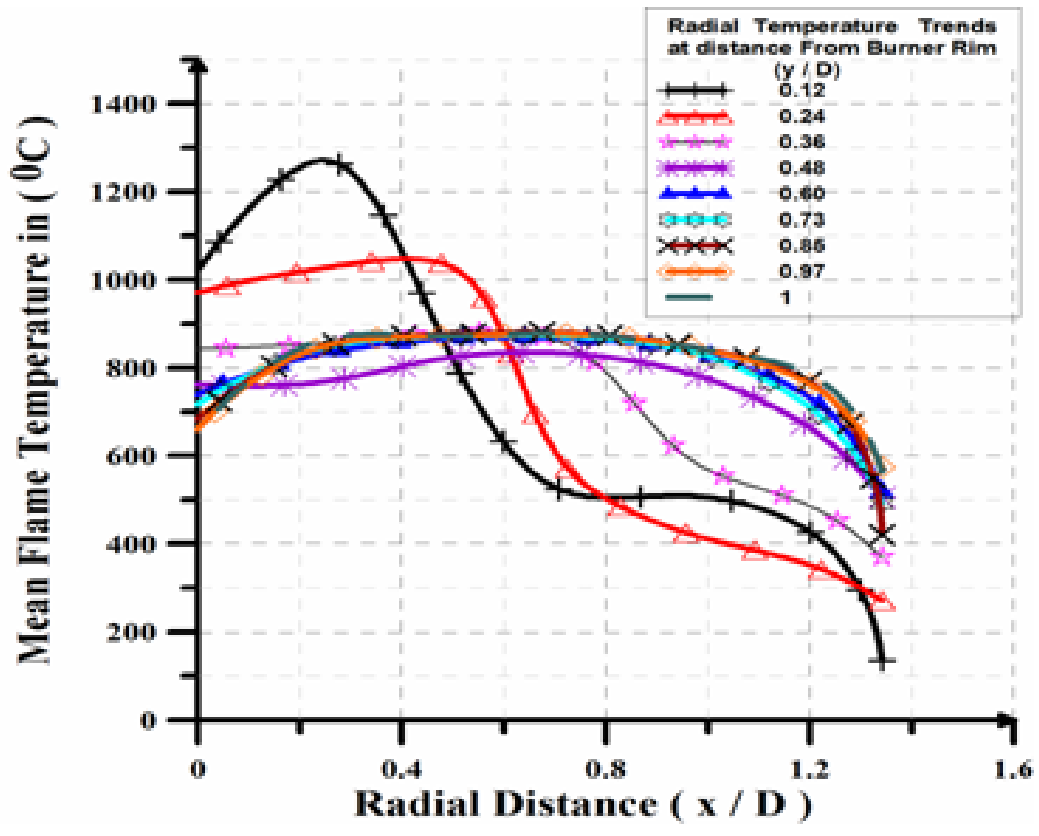

Figure 16.Temperature distribution across the flame in run 3B.

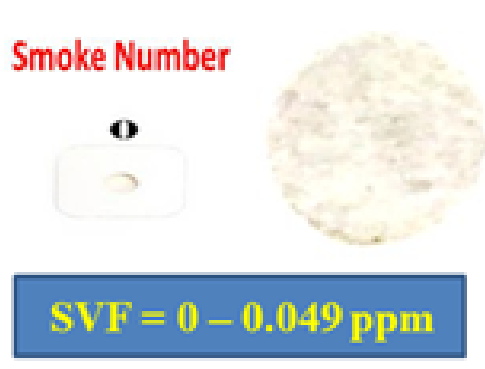

Figure 17. Smoke number at run $3 B$.

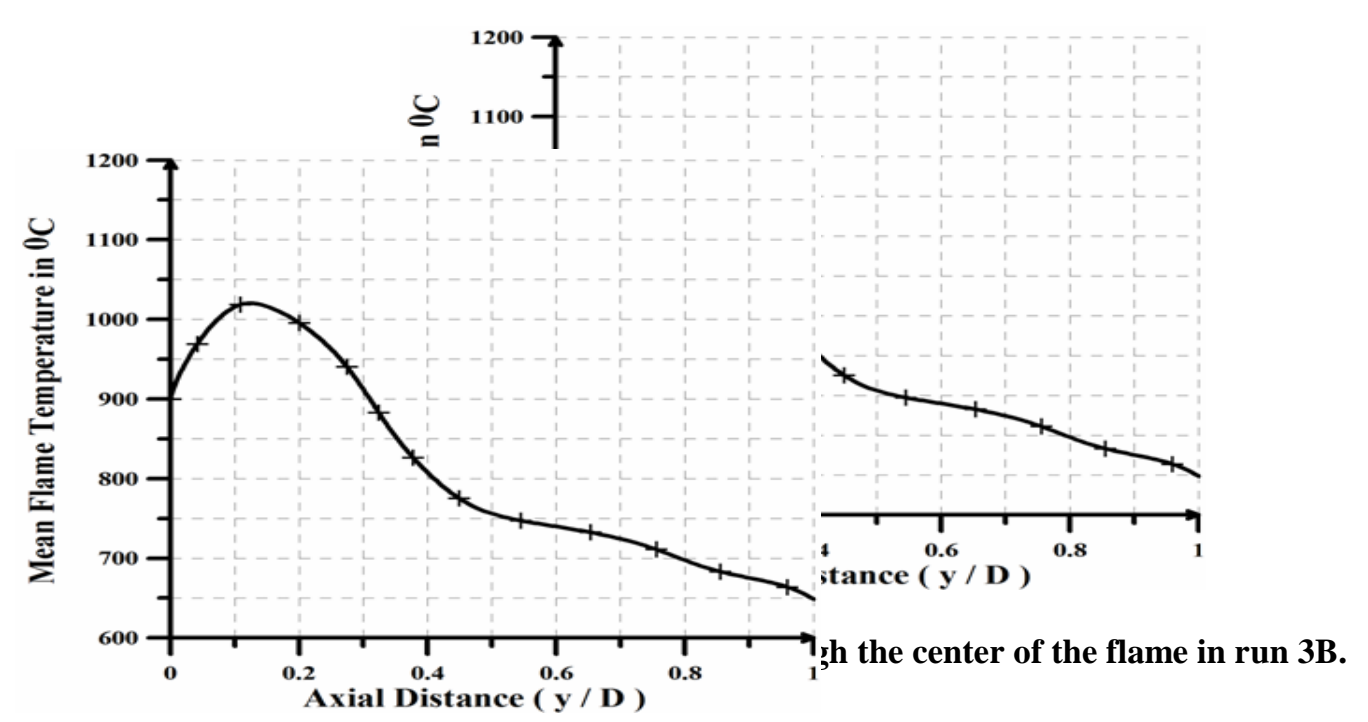




\section{Runs (1C and 3B):}

Figure (19) shows the influence of argon addition on mean flame temperature along axial distance at $\Phi=$ [ 0.8], Run [1C pure LPG, 3B mixture of LPG, Ar] It is obvious that the trend of mean flame temperature along the axial distance of EV burner was decreasing after addition of argon percentage on pure LPG. The maximum mean flame temperature was $1091.2^{\circ} \mathrm{C}$ and the exhaust temperature was $670.2^{\circ} \mathrm{C}$ in case of pure LPG and decreased to be $1020.2^{\circ} \mathrm{C}, 649^{\circ} \mathrm{C}$ respectively, in case of mixture of LPG \& Argon .

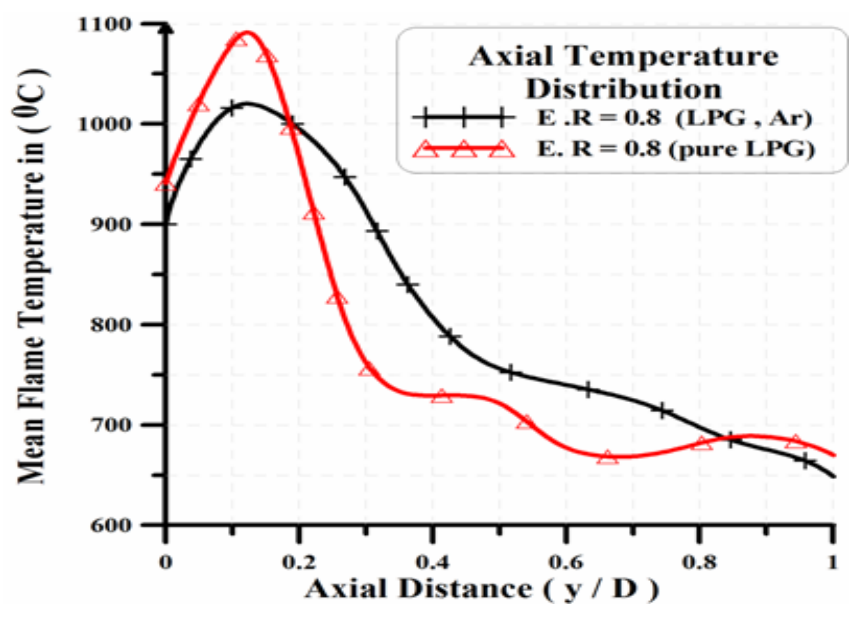

Figure 19. Influence of Argon addition on mean flame temperature along axial distance at $\Phi=[0.8]$, Run $[1 \mathrm{C}-3 \mathrm{~B}]$.

\section{Runs (2A to $2 \mathrm{C} \& 3 \mathrm{~A}$ to $3 \mathrm{C})$ :}

Figure 20 panels $\mathrm{a}, \mathrm{b}$ shows the variations of the exhaust temperature, NOx with the input volume flow rate of LPG \& Ar flames runs ( $2 \mathrm{~A}$ to $2 \mathrm{C} \& 3 \mathrm{~A}$ to $3 \mathrm{C}$ ) which indicates the decrease of the exhaust temperature, NOx ranges with the increasing of the addition of Argon percentage to the pure LPG and this is due to the temperature reductions resulting from the higher thermal capacity of Argon (diluent) and the lower heating value of the fuel mixture.

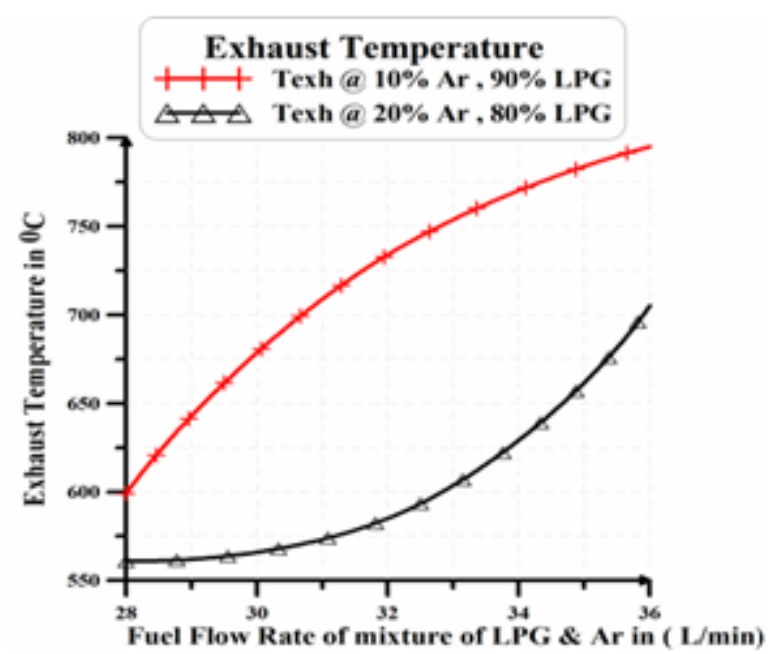

Panel a: variation of exhaust temperature with the flow rate of a mixture LPG and Argon. 


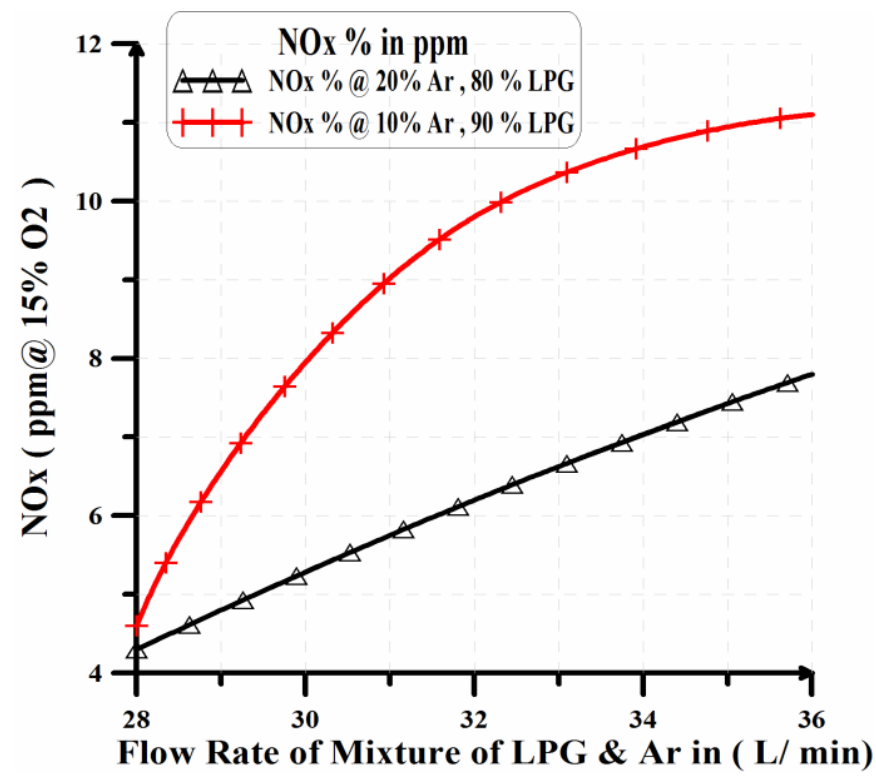

Panel b: variation of NOx emissions with the flow rate of a mixture LPG and Argon.

Figure 20. Panels a, $b$ variation of exhaust temperature and NOx with input volume flow rate of mixture LPG and Argon.

\section{Runs (2A to $2 \mathrm{C}, 3 \mathrm{~A}$ to $3 \mathrm{C}, 4 \mathrm{~A}$ to $4 \mathrm{C}$ ):}

Figure 21 shows the relation between combustion efficiency and the flow rates of LPG and Argon flames, runs (2A to $2 \mathrm{C}, 3 \mathrm{~A}$ to $3 \mathrm{C}, 4 \mathrm{~A}$ to $4 \mathrm{C}(3,3 \mathrm{~A}, 3 \mathrm{~B}, 3 \mathrm{C}, 3 \mathrm{D})$. It was noticed that the combustion efficiency trend decreasing by increasing the Argon \% addition while decreasing LPG percentage. Figure 22 panels a,b,c show the variations in the digital flame images associated with the progressive addition (10\% to 30\%) of Argon (diluent) to the base fuel (LPG) at different fuel flow rates for any particular mixture; (see also Table (2) .The following observations and interpretation may be outlined as follows:

1- Referring to Figure 22 panels a,b,c it is clearly seen that: The progressive increases of Argon at any particular fuel flow rate cause a decrease in the visible flame length. This visible length is lower than that in the pure LPG cases at the same input volumetric fuel flow rate. Also at any particular degree of Argon dilution, the visible flame length does not linearly increase with the progressive increase of the fuel mixture low rate; a typical characteristic of turbulent premixed flame. But the stream lines of the flame increases linearly with the progressive increase of the fuel mixture flow rate.

2- The degree of flame luminosity decreases with the increase of Argon dilution at any particular fuel flow rate; a fact which reflects an overall decrease of the local flame temperatures as a reason of (i) the lower degree of mixing between reactants and oxidant, (ii) the temperature reductions resulting from the higher thermal capacity of argon (diluent) and (iii) the lower heating value of the fuel mixture. 3- With the progressive increase of Argon flow rate, figure (21) Indicate that the flame length (Lf) increased in all runs. 
AN INVESTIGATION OF ARGON GAS ADDITIVES TO LPG ON THE TURBULENT LEAN PREMIXED FLAME CHARACTERISTICS FOR EV BURNER

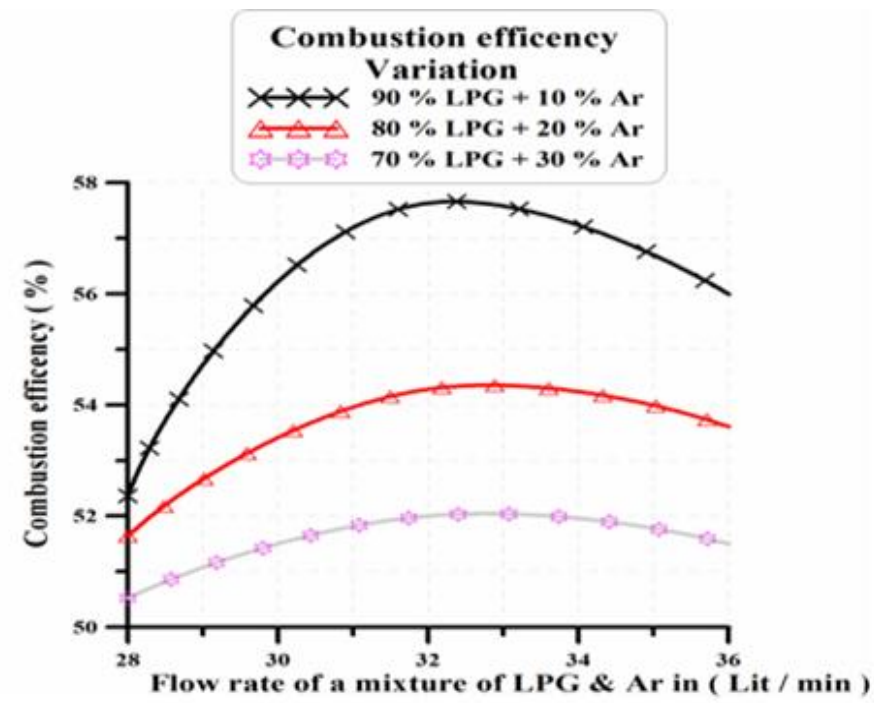

Figure 21. Variation of combustion efficiency with input volume flow rate of mixture of LPG and Argon at different percentages runs ( $2 \mathrm{~A}$ to $2 \mathrm{C}, 3 \mathrm{~A}$ to $3 \mathrm{D}, 4 \mathrm{~A}$ to $4 \mathrm{D})$.
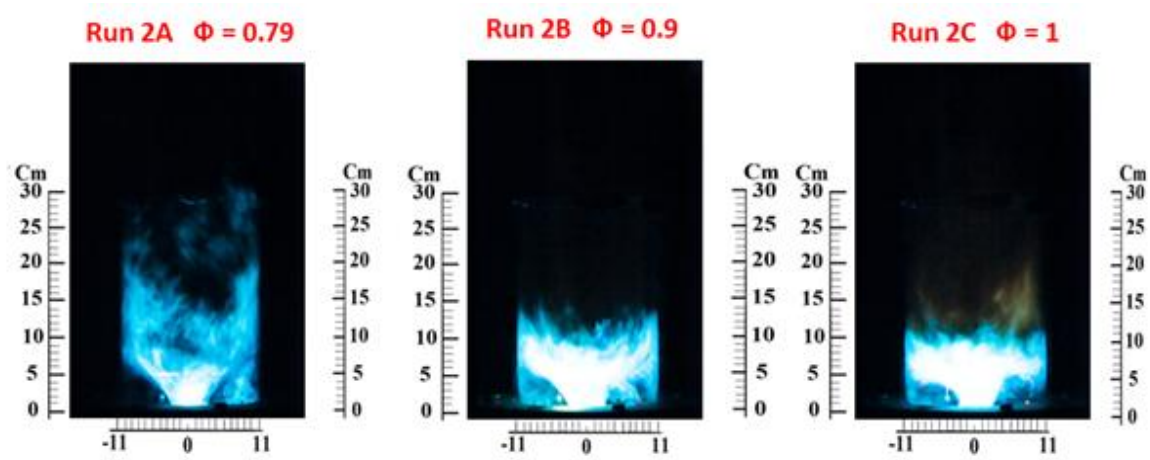

Panel a (Mixture 90\% LPG with 10\% Ar);[Runs 2A to2C].
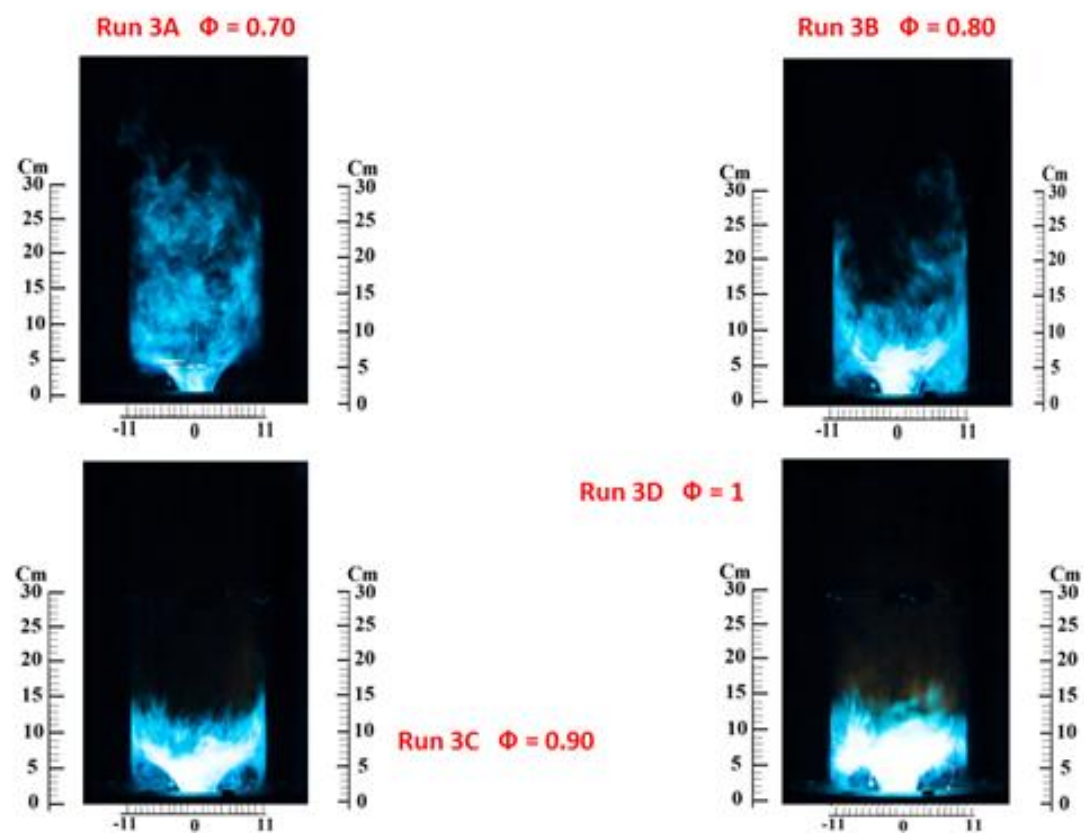

Panel b (Mixture 80\% LPG with 20\% Ar); [Runs 3Ato 3D]. 

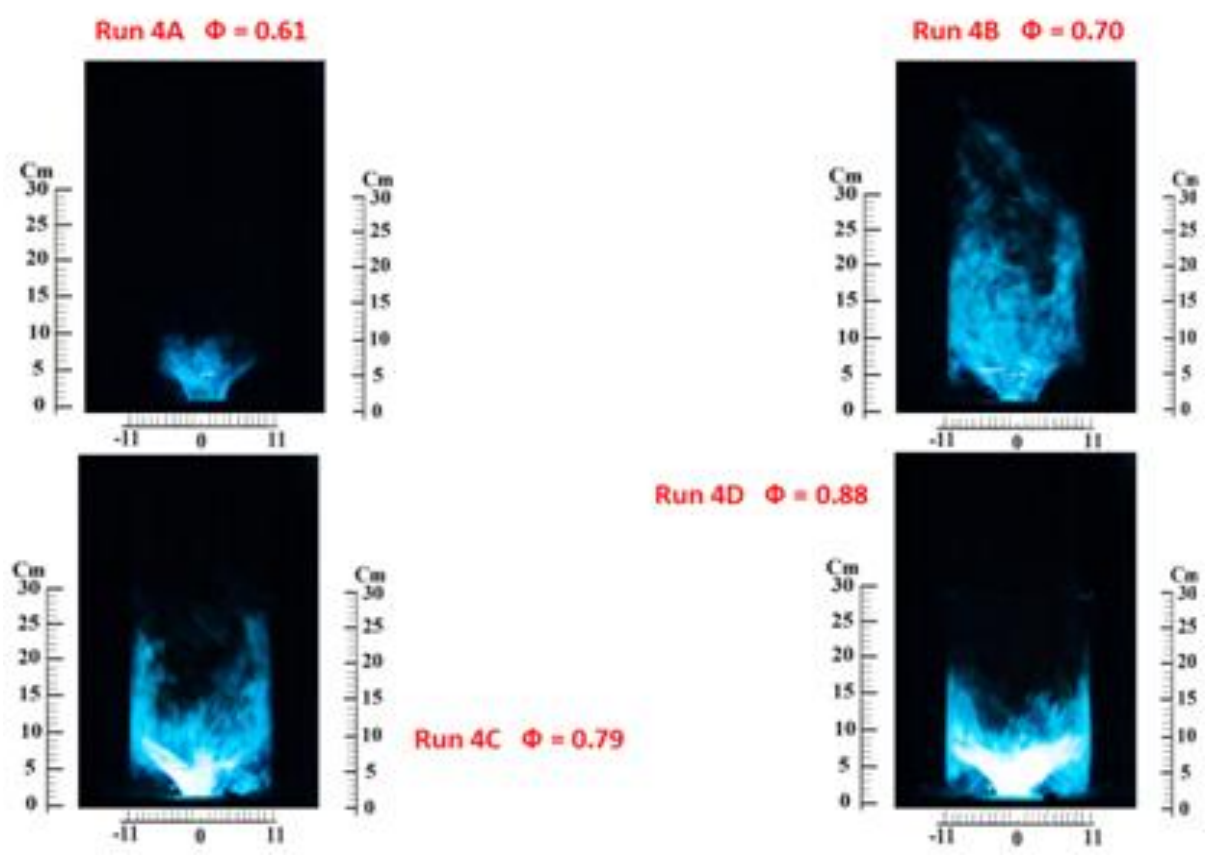

Panel c (Mixture 70\% LPG with 30\% Ar); [Runs 4A to 4D].

Figure 22. Panels a, b, c visual images of LPG with argon diluents turbulent lean premixed flames at. $(10-20-30 \%$ Argon $)$ addition

\section{CONCLUSIONS}

The investigation of injected mixtures of air, LPG, Argon in different concentrations on a coflowing jet turbulent lean premixed flames and their analysis for the mentioned 16 Runs in Table 2A, 2B of the experimental program lead to the following conclusions : -

\section{Concerning the visual analysis of the flame structure:}

- The whole flame located at the environmental (EV) burner center line in all cases.

- The stream lines of the flames increases with increasing volume flow rate in all cases.

- In the case of pure LPG only, the flame images starting from lower flow rates $24 \mathrm{l} / \mathrm{min}$, show short light blue flames and by incremental increases of the fuel flow rate this color changed to dark blue flames at flow rate $26 \mathrm{l} / \mathrm{min}$, then finally to yellowish and white luminous zones at Vlpg $=321 / \mathrm{min}$

- In case of LPG $+\mathrm{Ar}$, the stream lines of the flame increases linearly with the progressive increase of the fuel mixture flow, while the degree of luminosity decreases with the increase of Argon dilution at any particular fuel flow rate. The Argon addition make a decrease of the local flame temperatures as a reason of lower degree of mixing between reactants and oxidant.

\section{Concerning the analysis of the variations in the thermal structures:}

- In case of pure LPG the maximum axial flame temperature at $\Phi=0.8,1$ was $1091{ }^{\circ} \mathrm{C}, 1191^{\circ} \mathrm{C}$ respectively. By Argon addition to LPG the maximum axial flame temperature at $\Phi=0.8$ was $1039^{\circ} \mathrm{C}$.

- The radial distributions of mean gas temperature along the flame length clearly indicate that the maximum temperature was at the flame center (visible flame) in all cases. While the temperature started to decrease gradually until reach the flame outer boundary (invisible flame) attached to the combustor wall. 


\section{Concerning the analysis of the variations in smoke number and soot volume fraction:}

- In case of pure LPG only the smoke number is $=1$, SVF ranges $=0.05-0.09 \mathrm{ppm}$. By Argon addition to LPG the smoke number indicator decreased to zero, SVF ranges $=0-0.049 \mathrm{ppm}$.

Concerning the analysis of the variations in exhaust temperature:

- In case of pure LPG the exhaust temperature increases by the increasing the fuel flow rate of LPG. By Argon addition to LPG the exhaust temperature trends show a decrease in its ranges due to the temperature reductions resulting from the higher thermal capacity of Argon (diluent) and the lower heating value of the fuel mixture.

Concerning the analysis of NOx , combustion efficiency:

- In case of pure LPG the NOx emissions were increasing by increasing of pure LPG flow rates. While combustion efficiency maximum value around 56.14\% at $\Phi=1$. By Argon addition to LPG It was noticed that the NOx trend and combustion efficiency decreased by increasing the Ar \% addition while decreasing LPG \%.

The most important concluded benefits which can be applied practically from this experimental program are as follows :-

- Assess and measure the flame structure and soot formation for the most commonly used gaseous fuels in Egypt, especially LPG

- Mapping the soot volume fractions to trace the soot paths through the flame.

- Investigate the influence of different argon additives to LPG on the flame structure and soot formation at different flame conditions.

- The addition of argon additives to LPG decrease the axial flame temperature generated from the EV burner and also decrease the smoke number and the soot volume fraction (SVF) concentration and NOx and these recommendations can be applied in the most environmental (EV) burner used in the most electrical power plants used in Egypt

\section{REFERENCES}

[1]. Rankin, D.D., "Lean Combustion: Fundamentals, Applications, and Prospects", Academic Press. Elsevier, Irvine, California, 2007.

[2]. Yang, V., and Lieuwen, T. C., "Combustion Instabilities in Gas turbine engines: Operational experience, fundament Mechanisms, and Modeling", Vol.210 Progress in Astronautics and Aeronautics, Arlington, Texas, 2005.

[3]. Emara, A., Lacarelle, A., Paschereit, C. O., "Pilot Flame Impact on Flow Fields and Combustion Performances in a Swirl inducing Burner", AIAA 2009-5015, August 2009, Denver, Colorado, USA.

[4]. A.Hussien, "Effect of Geometrical and Opening Parameters on Exhaust Emissions for an Aerodynamically Air-staged Combustor."pp. pp1397- 1409.

[5]. S. Habik, and F. Elmahalawy, -Fundamentals and technology of combustion, Elsevier, 2002.

[6]. Guyot, D., and Paschereit, C. O., "Active control of combustion instability using symmetric and asymmetric premixed fuel modulation" ASME paper GT2007- 27342, Montreal, Canada, 2007.M

[7]. Duwig, C., Fuchs, L., Lacarelle, A., Beutke, M., and Paschereit, C. O.,"Study of the vortex breakdown in a conical swirler using LDV, LES and POD", ASME paper GT2007-27006, Montreal, Canada, 2007.

[8]. Albrecht, P., Bauermeister, F., Bothien, M., Lacarelle, A., Moeck, J., Paschereit, C. O., and Gutmark, E., "Characteriz ation and control of lean blowout using periodically centered flame balls", ASME paper GT2006- 90340, Barcelona, Spain, 2006.

[9]. Lacarelle, A., Luchtenburg, D. M., Bothien, M. R., Noack, B. R., and Paschereit, C. O., "A combinationof image post-processing tool to identify coherent structures of premixed flames", ICJWSF, Berlin Germany, 2008.

[10]. Li .W. F, Liu .Z. C, Tian. J, Wang. Z. S, Xu. Y, 2015, "Effects of argon dilution on the thermal efficiency and exhaust emissions of a NG engine ", International Journal of 
Automotive Technology, Volume 16, Issue 5, pp 721-731

[11] Periodic Table of Elements:Argon-Ar.(2008). http://wwwenvironmentalchemistry.com

[12]. Wright, J. R., (1961),"Effect of Oxygen on Carbon-Tendencies of Diffusion Flames", Fuel, Vol. 53, pp. 232-235.

[13]. P.A.Lakshminarayanan, S., Aswin, Simpson and Company LTD., Chenna"Estimation of Particulate Matter from Smoke Oil consumption and Fuel Sculpture",SAE Technical Paper 2016-32- 0066, 2016.

[14]. Schug K.P., Manheirner-Timmat, Y.,Yaccarino, P.and Glassman,I., "Sooting Behavior of Gaseous Hydrocarbon Diffusion Flames and the influence of Additives", Combust. Sci. and Tech., 22, 235-250, (1980).

[15]. Gay, N. R., Agnew, J. T., Witzell, O. W. and Karabell, C. E., (1961), "Thermo chemical Equilibrium in Hydrocarbon-Oxygen Reactions Involving Polyatomic Forms of Carbon", Combustion and Flame, Vol. 5, pp. 257-272.

[16]. Emara, A., "Interaction of flow field and combustion characteristics in a Swirl stabilized burner - Ph.D. thesis, Technical university, Berlin, Germany, 2011.

[17]. Sameh Hassan, A.Emara, M. Elkady,"Evaluation of EV Burner Performance through Pilot Injection Technology: A Review", ISSN 23213361 @ 2016 IJESC.

[18]. Shannon .K.S, . Butler. B.W, (2002) "A review of error associated with thermocouple temperature measurement in fire environments," USDA Forest Service, Fire Sciences Laboratory, Rocky Mountain Research Station Missoula, Montana.

[19]. Shaddix, Christopher R., (1998) "Practical aspects of correcting thermocouple measurements for radiation loss." Fall Meeting of Western States Section/The Combustion Institute.

[20]. Jones, J.C., (1995) "On the use of metal sheathed thermocouples in a hot gas layer originating from a room fire". Journal of Fire Science, 13,257-260. 